\title{
Evidentiality in Academic Writing
}

\author{
Mojdeh Ebrahimi Dehkordi \\ Islamic Azad University, Shahreza Branch, Isfahan, Iran \\ Email: mojdeh_ebrahimy@yahoo.com \\ Hamid Allami \\ Yazd University, Yazd, Iran \\ Email: hallami@yazduni.ac.ir; hamid_allami@yahoo.com
}

\begin{abstract}
Inevitability of using evidentials (EVs) and references in all academic writings signifies the importance of distinguishing and applying EVs for those who attempt to write in academic prose. With the aim of creating a unique model of EVs in academic texts, this study used well-established taxonomies of metadiscourse markers adapted by Hyland (2005) combined with Swales' (1990) classification of citations as well as Berkenkotter and Huckin's (1995) concept of intertexuality in academic writing. The proposed model yields at least two important advantages. First, it can develop a pattern of the uses of EVs in academic texts, thus deepening our understanding of the organization of such texts. Second, it has potential applications in pedagogy for those students who attempt to write in academic prose and for scholars, teachers, and material developers.
\end{abstract}

Index Terms—evidentials, referencing, metadiscourse, academic writing

\section{INTRODUCTION}

Metadiscourse as a common term in current discourse analysis is based on a view of writing or speaking as a social engagement (Dafouz-Milne, 2008; Hyland, 2005). As Hyland (2005) said: "Metadiscourse incarnates the idea that writing and speaking are not just the exchange of information, goods or services, but rather involves the personalities, attitudes and assumptions of the people who are communicating" (p. 3). Metadiscourse elements are then social acts which include writers, readers, speakers and listeners to interact with each other and in fact, impact the ways ideas are presented and understood. Metadiscourse is, therefore, considered as an important aspect of communication in that it helps to evaluate the readers' or listeners' resources for understanding the text and their probable responses to it to be able to effectively write or speak. Primarily, it is used by researchers to trace patterns of interaction, and to discuss different aspects of language in use. As defined by Hyland (2000, p. 109), it is 'the linguistic resources used to organize a discourse or the writer's stance towards either its content or the reader'.

Citing the primary source can play a decisive role for the credibility of information, especially with sources that have high levels of societal legitimacy. Everyday conversations often make detours in lexicon discourse such as, "How do you know this?" or "Were you there?" It is generally agreed that writers do not simply give neutral facts but make an attempt to show their own viewpoints to their readers, thus raising interests in the way that writers present their propositional content, their feelings and evaluations (Conrad \& Biber, 2000; Hunston \& Thompson, 2003; Thompson, 1996).

In order to reflect their views and convince readers, writers in academic discourse put different sources to use, one of which is citation (Thompson, 2006). In some languages there are grammatical elements like affixes and particles that determine the source of the information being communicated (i.e., whether it is obtained by perception, inference, or hearsay). These markers are parts of what is labeled as evidentiality (Aikhenvald, 2004). In another sense, evidentiality means marking the sources of information (Aikhenvald, 2004; Hardman, 1986). In a broader sense, the term evidentiality is more often used to refer to the source as well as to the reliability of the writer's knowledge (Dendale \& Tasmowski, 2001).

An essential aspect of successful academic writing is making references to the literature. Reference making is also a source of considerable difficulty for most inexperienced writers (Borg, 2000; Campbell, 1990). According to Hyland (2005), in academic writing "evidentiality refers to a community-based literature and provides important support for arguments" (p. 50). As Hyland, (2000) stated, the citation of other texts is important at one of two levels: reference to other researchers' work or ideas can provide support for one's own position; it can also show the newness of one's work. Moreover, it can be helpful in pointing out the weaknesses in others' arguments, aligning themselves with a particular camp/school/grouping (Thompson \& Tribble, 2001).

Myers (1990) maintains that references assist researchers with describing the present state of knowledge so that the writers can then make their claims within the larger disciplinary framework, and establish a narrative context. Inexperienced writers may encounter problems because of not being at the proper stage of cognitive or intellectual development (Britton, Burgess, Martin, McLeod, \& Rosen, 1975; Pennycook, 1996), or because of cultural factors 
(Connor, 1999; Fox, 1994). Failure to acknowledge the source of ideas can lead to charges of plagiarism, whereas inexpert phrasing of reporting statements can lead to confused or misleading indication of both the writer's and the cited author's stance (Groom, 2000).

All writers are aware that EVs give credibility and quality to their expressions and "that without them a research article could be seriously questioned, if not immediately rejected" (Abdi, 2009). Thus, the present study assumes that the function of EVs is to indicate sources of information outside the text in general, and facilitate the interaction between the writer and the reader, in particular. The function of EVs is not only indicating the source outside the text, but also providing a link between the writer's own statements and other writer' statements, thus creating intertextuality. Intertextuality is extremely important in academic writing, where writers constantly have to establish their academic claims by creating new knowledge and showing how it relates to the past or accepted knowledge in a specific field by a specific discourse community.

\section{CONCEPTUAL FrAMEWORK}

Following Crismore, A., Markkanen, R., \& Steffensen, M. (1993) distinction in categorizing textual and interpersonal types of metadiscourse, Hyland proposed a new model of metadiscourse in academic texts. His model assumes two main categories of interactive and interactional metadiscourse. According to Hyland (2005), interactive resources of metadiscourse include strategies of transitions, frame markers, endophoric markers, EVs and code glosses that help to guide the reader through the text; EVs here indicate the external origin of material in the current text and adds credence to the researched documents by drawing attention to the credibility of its source. The interactional resources of metadiscourse consists of hedges, boosters, attitude markers, self-mentions and engagement markers strategies which help to involve the reader in the argument. Following Hyland (2005), this study uses the term 'EVs' from a new perspective and in fact, proposes a new categorization for this concept in academic texts.

As mentioned above, EVs are strategies used by writers to refer to other texts as sources of additional information; they guide the readers through the text and help them in recovering the writers' intentions (Hyland \& Tse, 2004). As Thomas and Hawes, (1994) state, EVs are 'metalinguistic representations of an idea from another source' (p. 129). Hyland distinguishing academic writing from other genres states that "In some genres this may involve hearsay or attribution to a reliable source; [but], in academic writing it refers to a community-based literature and provides important support for arguments" (p. 51). In fact, by EVs we can distinguish who is responsible for a position. As Hyland (1998) states, EVs perform a similar metadiscoursal role by indicating the source of textual information which originates outside the current text. They, therefore, assist in guiding the reader's interpretation and establishing intertextuality, capturing the need for academics to display knowledge of other texts in the field.

In some discourse studies of the interaction between the writer and the reader (see Tadros, 1995) the concept of attribution is used to explore ways that writers use to signal other texts as sources of authority. In some earlier models of metadiscourse (e. g. Crismore, 1993 in Connor, 1999) the term 'attributor' is used to name the linguistic resources which have the function of referring to information from other texts. The current study considers the terms evidentials, attributors and citations synonymously, as it sees them as having the same metadiscoursal functions, but following the model proposed by Hyland (2005) uses the term evidentiality and EVs to indicate the origin of textual information outside the current text and by focusing on these devices proposed the new classification for the concept and tried to analyze it in different sub-categories. Here are a few examples of EVs taken from physical and social sciences RAs:

1. As a leading author of texts on trial techniques stated, "If you don't [divulge the information], your opponent will with twice the impact" (Mauet, 1992, pp. 47-48). (Management article)

2. Gana, Martin, and Canouet (2001) have suggested that worry produces anxiety, which in turn, indirectly affects depression. (Psychology article)

3. One of the most important distinctions that has emerged from this research is that the goal of variable selection in discriminant analysis depends on whether the analyst's objective is description or allocation (McKay and Campbell, 1982a). (Computer article)

4. An additional challenge for SBLO-1 and mammalian 15-lipoxygenase is to account for the fact that these enzymes will oxygenate not only free fatty acids but also larger substrates such as phospholipids [10-12, 25]. (Chemistry article)

5. Many researchers studied the role of three factors namely "Human", "Road and Environment" (In this article briefly called "Road") and "Vehicle or Car" in severity of road crashes. (Computer article)

6. There have been many attempts to improve variable selection in discriminant analysis (see, for example, Roy, 1958; Weiner and Dunn, 1966; Horton et al., 1968; Urbakh, 1971; .....) (Computer article)

7. Recent literature has focused primarily on the hold-up problem encountered in transaction cost economics (TCE, e.g. Dekker, 2004; Langfield-Smith and Smith, 2003; Oxley, 1997). (Management article)

\section{REVIEWING THE LITERATURE}

The metadiscourse or metatext in modern applied linguistics is a part of spoken or written discourse - "the linguistic material in text that does not add anything to the propositional content but that is intended to help the listener or reader organize, interpret, and evaluate the information given." (Crismore et al., 1993, p. 41). Crismore (1993) also has defined 
metadiscourse as "the author's intrusion into the discourse, either explicitly or non-explicitly, to direct rather than inform the readers" (p. 4). Although there are different definitions in this regard, most scholars agree that metadiscourse is as important as the primary discourse. They believe that metadiscourse is essential for the appropriate construction of any piece of writing. Metadiscourse goes beyond what is being talked about in speech or writing (or propositional content), which is presented through the discourse, making an integral part of it. As most linguists have stated, metadiscourse acts as a double-function phenomenon and organizes discourse and issues comments on it. It "allows writers to show readers how different parts of the text are related and how they should be interpreted, and also permits writers to express their attitudes toward the propositional content of the text and toward their readers' (Crismore et al., 1993).

In order to classify the linguistic units, many metadiscourse studies (see Crismore et al., 1993; Dafouz, 2003; Hyland, 1998; Vande Kopple, 1985, among others) have utilized the Hallidayan distinction between textual and interpersonal functions of language. Textual metadiscourse, sometimes referred to as metatext (Mauranen, 1993), is utilized to organize the text and direct the reader through the text. In fact, it performs Halliday's textual function. On the other hand, developing the relationship between the reader and the writer is the aim of Interpersonal metadiscourse. The interpersonal function of language will be fulfilled when, along with the first and second person pronouns, interpersonal metadiscourse markers are added to texts. Interpersonal metadiscourse is an important rhetorical strategy; according to Vande Kopple (1985) many discourses have at least two levels. At one level, the writer presents information about the subject of the text. Propositional content is expanded at this level. At the level of metadiscourse, the second level, the writer does not add propositional material. Instead, he helps the receivers organize, classify, interpret, evaluate and react to such materials. Metadiscourse, therefore, is discourse about discourse or communication about communication.

Although metadiscourse is a relatively new concept, it has generated a lot of research in recent years; there have been numerous studies of various aspects of metadiscourse (e.g. hedging, imperatives, self-mention) in a range of genres. A range of recent studies in text analysis have been devoted to the presence and functional role of metadiscourse markers in various genres including science popularizations (Crismore \& Farnsworth, 1990), textbooks (Crismore, 1983, 1984; Hyland, 1999), student writing (Simin \& Tavangar, 2009; Steffensen \& Cheng, 1996), advertisements (Fuertes-Olivera, P. A., Velasco-Sacristán, M., Arribas-Baño, A., \& Samiengo-Fernández, E., 2001), and research articles (Abdi, 2002; Hyland, 1998, 1999). Metadiscourse has also been used to examine rhetorical differences in the texts written by different first language groups (Crismore et al., 1993; Dahl, 2004; Mauranen, 1993) and those produced by EFL and native writers (Faghih \& Rahimpour, 2009).

Studies involved with evidentiality have revealed culture-specific and discipline-specific differences in the use of EVs in academic texts. For example, Tadros' (1995) study has shown how the use of citations in textbooks reflects the author purpose and reader orientation; Hyland and Tse's (2004) study has revealed interesting patterns in the use of EVs by biologists. Similarly, some other valuable attempts in this field are Bloch and Chi's (1995) study of the ways Chinese and Western scholars refer to prior texts in their academic writing, and Berkenkotter and Huckin's (1995) study that refers to citation, or referencing, as a 'textual mechanism' which establishes the context and helps the writer to provide 'intertextual' linkages.

In the metadiscourse literature, a number of taxonomies can be seen. (Adel, 2006; Crismore, 1989; Hyland, 2005; Vande Kopple, 1985, 2002). Metadiscoursal elements can be classified according to their meaning, forms and function. Using Halliday's (1973, 1985) macrofunctions of language, Vande Kopple (1985) has given a mainly functional classification. Halliday (1973) believed that when people use language, they usually work towards fulfilling three macrofunctions, by trying to provide expressions of their experience, to interact with their audience, and to organize their expressions into cohesive discourses whose addressees can make coherent sense. In other words, he asserts that people communicate with messages that are integrated expressions of three different kinds of meaning, which he calls ideational, textual, and interpersonal. Elements in ideational set are concerned with the expressions of our experience, "both of the external world and of the inner world of our own consciousness". Elsewhere, Vande kopple (1988) asserts that, elements within the textual set have "an enabling function of creating text, which is language in operation as distinct from strings of words or isolated sentences and clauses" (p. 242). Finally, the elements of interpersonal set have to do with "language as mediator of role". These elements include forms of interaction with participants as well as the expressions of personalities and personal feelings (Halliday, 1973).

The taxonomies which appear in Tables I to IV, demonstrate a theoretical fine-tuning as time develops.

The first model (Table I) was introduced by Vande kopple (1985). There were two main categories of metadiscourse in this model, namely textual and interpersonal. Textual metadiscourse consisted of four strategies: text connectives, code glosses, illocution markers and narrators. The interpersonal metadiscourse included three strategies, namely validity markers, attitude markers and commentaries.

Vande Kopple's model was specifically important in that it was the first systematic attempt to introduce a taxonomy that triggered lots of practical studies, motivated further closer analyses, and gave rise to new classifications. 
TABLE I.

METADISCOURSE CLASSIFICATION BY VANDE KOPPLE (1985, PP. 82-92)

\begin{tabular}{|c|c|}
\hline Category & Function \\
\hline \multicolumn{2}{|l|}{$\begin{array}{l}\text { Textual } \\
\text { metadiscourse }\end{array}$} \\
\hline Text connectives & $\begin{array}{l}\text { Used to help show how parts of a text are connected to one another. Includes seque ncers (first, next, in the second place), } \\
\text { reminders (as I mentioned in chapter } 2 \text { ), and topicalizers, which foc us attention on the topic of a text seg ment (with reg ard } \\
\text { to, in connection with). }\end{array}$ \\
\hline Code g losses & $\begin{array}{l}\text { Used to help readers to grasp the writer's intended meaning. Based on the writer's assessment of the reader's knowledge, } \\
\text { these devices reward, explain, define, or clarify the sense of a usage }\end{array}$ \\
\hline Validity markers & $\begin{array}{l}\text { Used to express the writer's commitment to the probability of or truth of a statement. These include he dges(perhape, } \\
\text { might, may), emphatic (cle arly, undoubte dly), and attributers which enhance a position by claiming the support of a } \\
\text { credible otsher(according to Einstein) }\end{array}$ \\
\hline Namators & $\begin{array}{l}\text { Used to inform readers of the source of the information presented- who said or wrote something (according to smith, the } \\
\text { Prime minister announced that). }\end{array}$ \\
\hline \multicolumn{2}{|l|}{$\begin{array}{l}\text { Interpersonal } \\
\text { metadiscourse }\end{array}$} \\
\hline Illocution markers & $\begin{array}{l}\text { Used to make explicit the discourse acts the writer is performing at certain points(to conclude, I hypothesize, to sum up, } \\
\text { we predict) }\end{array}$ \\
\hline Attitude markers & $\begin{array}{l}\text { Used to express the writer's attitudes to the propositional mate rial he or she presents unfortunately, interestingly, I wrish } \\
\text { that, how awful that). }\end{array}$ \\
\hline commentaries & $\begin{array}{l}\text { Used to address readers directly, drawing them into an implicit dialogue by commenting on the reader's probable mood or } \\
\text { possible reaction to the text(you will certainly agree that, you might want the third chapter first). }\end{array}$ \\
\hline
\end{tabular}

The revised model (Table II) was introduced by Crismore et al. (1993). Keeping Vande Kopple's two major categories of textual and interpersonal, they collapsed, separated and reorganized the subcategories. In an attempt to separate organizational and evaluative functions, they further divided the textual metadiscourse into two subcategories of textual and interpretive markers. Moreover, validity marking, under different name-certainty markers- was moved from textual category to interpersonal category.

TABLE II.

METADISCOURSE CATEGORIZATION BY CRISMORE ET AL. (1993, PP. 47-54)

\begin{tabular}{|c|c|c|}
\hline Category & Function & Examples \\
\hline \multicolumn{3}{|c|}{ Textual metadiscourse } \\
\hline \multicolumn{3}{|l|}{ 1. Textual markers } \\
\hline Logical connec tives & Show connection between ide as & Therefore; so; in addition; and \\
\hline Sequencers & Indicate sequence fordering of material & First, next; finslly, $1,2,3$ \\
\hline Reminders & Refer to earlier text material & As we sw in chapter one \\
\hline Topicalizers & Indicate a shift in topic & Well, now we dixuss. \\
\hline \multicolumn{3}{|l|}{ 2.Interpre tive markers } \\
\hline Code glosses & Explain text material & For example; that is \\
\hline Illocution markers & Name the act performed & To conclude ; in sum; I predict \\
\hline Announcements & Anno unce upcoming material & In the next section \\
\hline \multicolumn{3}{|c|}{ Inte rperonal metadixourse } \\
\hline Hedges & Show uncertainty to the truth of assertion & Might; possible; likely \\
\hline Certainty markers & Expres full commitment to assertion & Certainly, know, shows \\
\hline Attrbuters & Give source/support of information & Smith claims that. \\
\hline Attitude markers & Display writer's affective values & I hope fagree; surgrisingly \\
\hline Commentary & Buld relationship with reader & You may not agree that \\
\hline
\end{tabular}

A more recent model (Table III) introduced by Adel (2006) indicated a different theoretical view. It was different in that she separated evaluation from metadiscourse and questions non-propositionality as the criterion for metadiscourse.

TABLE III.

ADEL'S METADISCOURSE MODEL (2006, P. 38)

\begin{tabular}{|c|c|c|c|c|c|}
\hline $\begin{array}{l}\text { Metadiscourse } \\
\text { Metatext } \\
\text { Impersonal } \\
\text { TextClCode-oriented }\end{array}$ & $\begin{array}{l}\text { Personal } \\
\text { Participant- } \\
\text { oniented }\end{array}$ & Writer-oriented & Reader-oriented & $\begin{array}{l}\text { Writer-reader interac } \\
\text { Personal } \\
\text { Participant-oniented }\end{array}$ & $\begin{array}{l}\text { tion } \\
\text { Reade }- \text {-oriented }\end{array}$ \\
\hline 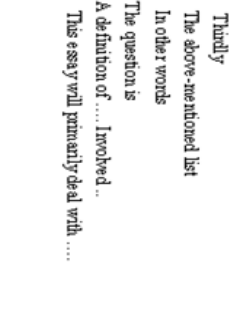 & 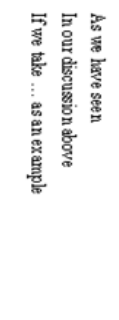 & 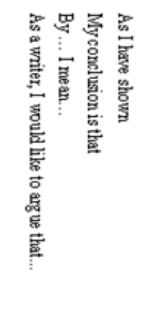 & 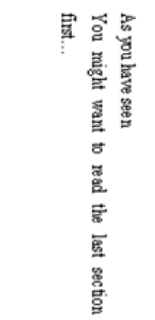 & 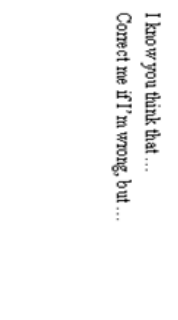 & 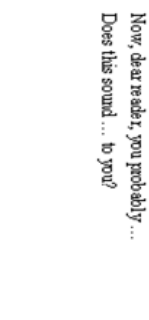 \\
\hline
\end{tabular}

The model proposed by Hyland (2005) assumes the two main categories of interactive and interactional for metadiscourse following the distinction made by Thompson and Thetela (1995) to acknowledge the organizational and evaluative features of interaction (Table IV). 
TABLE IV.

A MODEL OF METADISCOURSE IN ACADEMIC TEXTS (HYLAND \& TSE, 2004, P. 169; HYLAND, 2005, P. 49)

\begin{tabular}{|c|c|c|}
\hline Category & Function & Examples \\
\hline Interactive & Help to guide the reader through the text & Resources \\
\hline Transitions & express relations betw een main clauses & in addition; but; thus, and \\
\hline Frame markers & refer to discourse acts, sequences or stages & $\begin{array}{l}\text { finally, to conclude, my } \\
\text { purpose is }\end{array}$ \\
\hline $\begin{array}{l}\text { Endophoric } \\
\text { markers }\end{array}$ & $\begin{array}{l}\text { refer to information in other parts of the } \\
\text { text }\end{array}$ & $\begin{array}{l}\text { noted above; see figure; in } \\
\text { section } 2\end{array}$ \\
\hline Evidentials & refer to information from other texts & according to $\mathrm{X} ; \mathrm{Z}$ states \\
\hline Code glosses & elaborate propositional meaning & $\begin{array}{l}\text { namely, e.g:; such as, in } \\
\text { otherwords }\end{array}$ \\
\hline Interactional & Involve the reader in the text & Resources \\
\hline Hedges & withhold commitment and open dialogue & $\begin{array}{l}\text { might; perhaps, possible, } \\
\text { about }\end{array}$ \\
\hline Boosters & emphasize certainty and close dialogue & $\begin{array}{l}\text { in fact, definitely, it is clear } \\
\text { that }\end{array}$ \\
\hline Attitude markers & expresses writers' attitude to proposition & $\begin{array}{l}\text { unfortunately, } \\
\text { surprisingly }\end{array}$ \\
\hline Self mentions & explicit reference to author(s) & I; we, my; me, our \\
\hline $\begin{array}{l}\text { Engagement } \\
\text { markers }\end{array}$ & explicitly build relationship with reader & $\begin{array}{l}\text { consider, note; you can see } \\
\text { that }\end{array}$ \\
\hline
\end{tabular}

As it can be seen in the table above, the interactive part includes the strategies of transitions, frame markers, endophoric markers, EVs and code glosses and the interactional part consists of hedges, boosters, attitude markers, selfmentions and engagement markers strategies. The model has drowned upon several earlier models.

Although notable differences can be seen among the models, the significance of metadiscourse in written communication, as well as variations in different contexts, is being demonstrated by several studies. No matter what theoretical standpoint is supported (Adel, 2006; Crismore, 1990; Hyland, 2004; Simin, 2004; Taylor, 2000; Thompson, 2001).

It should be noted that Hyland and Tse's (2004) definition of EVs as an interactive metadiscourse resource is a point of departure in this study and the proposed model of researchers was established on the basis of Hyland's introduction of such items.

In the literature, the use of EVs has been investigated together with other metadiscoursal strategies. According to the findings of studies conducted in this area, the differences found in the use of EVs in academic texts are culture-specific and discipline-specific. What follows is a summary of what has been done in this field.

Citation analysis, a relatively new area of study, has its origin in an initiative to start citation indexing by Garfield (1955), who was a pioneering information scientist. It has used three approaches (Liu, 1993; White, 2004) which indicate some similarity to those of discourse analysis. A criterion to judge the importance of a work within a discipline was the number of citations. This was based on the assumption that the more citations a paper obtains, the greater impact it has on the academic community (Cole \& Cole, 1971; Merton, 1973). In discourse analysis this can be compared to the quantitative analysis of linguistic forms, such as investigating the frequency of passive voice compared with active voice (Salager-Meyer, 1992).

In the most discourse analysis citations have often been investigated with regard to reporting verbs (Charles, 2006; Hunston \& Thompson, 2003; Hyland, 1999, 2001; Shaw, 1992; Thomas \& Hawes, 1994; Thompson \& Ye, 1991). As an example, Thompson and Ye (1991) studied the introduction sections of more than 100 papers to examine how writers demonstrate their evaluation of earlier work, and interact with their discourse community through the reporting verb. They also indicated that writers show their positive and negative evaluation of previous studies by their choice of reporting verbs. It seems that negative opinion is often presented in a more implied manner in context than positive evaluation (Thompson \& Ye, 1991) and may only be obvious to insiders of the discipline.

This perspective in citation-i.e. insiders' perspective - has been investigated in studies on citation analysis, which are closely related to the disciplines of information science and sociology of science (Cozzens, 1985; Small, 1982; Shadish, Tolliver, Gray and Gupta, 1995; Wang \& White, 1997). However, although integration of the results of studies on discourse analysis with citation analysis has long been proposed - early on by Swales (1986) and more recently by Harwood (2004) and White (2004) -, it still seems that researchers of these disciplines are not familiar with the achievements of one another (White, 2004). Since citation is essential in the analysis of academic texts (Hyland, 1999 \& 2000), researchers in discourse analysis can reap benefit from the findings of information science and sociology of science.

In spite of some real efforts to classify the content of citations, the restrictions of this approach became clear. Firstly, one citation may belong to more than one category (Cano, 1989; Chubin \& Moitra, 1975). Secondly, based on the findings of Moravcsik \& Murugesan' (1975) study on 30 theoretical high energy physics papers published in Physical Review, it was not possible to apply the same categories across the disciplines (Chubin \& Moitra, 1975). Last but importantly, as MacRoberts and MacRoberts (1984) asserted, the linguistic analysis of citation does not always demonstrate the writer's real aim because writers may reduce their critical comments, which leads to demands for 
understanding of the writers' intentions behind the citation. Therefore, the above-mentioned limitations of content analysis guided the researchers to investigate the real reasons for citation, i.e. the citers' motives (Brooks, 1986; Budd, 1999; Cronin, 1998; Shadish et al., 1995; Wang \& White, 1999; White, 2004). Based on either normative theory or on a micro-sociological perspective, two types of motivation were suggested (Liu, 1997). The first one assumes that citation is for granting merit. This was originally considered to be the main reason for citation (Cole \& Cole, 1967, 1976; Davenport \& Cronin, 2000; Merton, 1973), because citation is part of the collective activity of knowledge construction in the discourse community. In contrast, the second one gives reasons for persuasion: the citer's knowledge claim being seen as the major motivating factor in citation (Brooks, 1984; Case \& Higgins, 2000; Latour, 1987). Gilbert (1977) in his influential paper claimed strongly that writers cite in order to convince their readers. This argument had such an impact that it changed attention from citation itself to the role of citation in a text, examining the individual writers' standpoint rather than that of the discourse community. However, others maintained that the choice of citation would not be based on the researchers' names but the content of the work (Cozzens, 1989; Zuckerman, 1987). By presenting the idea of "rhetoric first, reward second" following studies have done to balance the argument (Cozzens, 1989), and the interviews with writers of academic texts concerning the motivation for citation have confirmed this claim (Case \& Higgins, 2000; Shadish et.al, 1995; Vinkler, 1998; Wang \& White, 1999).

Hyland in his studies (1999 and 2000) combined interviews with academics and analysis of a large corpus of academic texts which revealed similar viewpoints of the citers' motivation to those found in citation analysis (Brooks, 1986; Cozzens, 1989). He maintained "reference to previous work is virtually mandatory in academic articles as a means of meeting priority obligations and as a strategy for supporting current claims" (Hyland, 1999, p. 362).

While discourse analysis could further investigate the aims of citation forms, citation analysis concentrates on the use of citation itself. The purposes of citation forms may be the same as those of citation found in citation studies. The findings in this area of study demonstrate that social science disciplines like politics utilize more integral citation forms than do natural sciences (Charles, 2006; Hyland, 1999).

Some researchers such as Swales (1981, 1986, and 1990) have looked at the study of citation analysis from an applied linguistic viewpoint. Swales (1986) reviewed the work on citations that has been conducted in other disciplines, such as in citation analysis and in the sociology of science although for completely different purposes. The development of a method to count the number of positive citations in a paper, to rank its quality has been one of citation analysis aims. According to Moravcsik and Murugesan (1975), just counting the number of references that a paper draws in other publications is not enough, because some of those citations could be negative, or they might be superficial. The original categorization of citation forms was developed by Swales (1986). He examined the different attempts to build a model of citation types and then proposed his own model. In his model, the first distinction is between citation forms that are non-integral and those that are integral: the non-integral forms are citations outside the sentence and usually placed within brackets and have no explicit grammatical roles in the sentence. On the other hand, the non-integral forms play an explicit grammatical role within a sentence. The citation at the beginning of this paragraph, for example, is an integral citation, and the reference to Charles and Hyland, in the last sentence of the previous paragraph, is a nonintegral citation.

A few studies in the literature have examined the differences in the use of citation between L1 and L2 writers in published academic texts. L2 professional writers possess the same knowledge about citation practices, but in the realization of citation forms in their own texts, L2 professional writers may not always be as linguistically skillful as L1 professional writers. This was shown in an analysis of covering letters written by L1 and L2 professionals accompanying a manuscript for publication (Okamura \& Shaw, 2000). The proposed model of classification EVs in this study intends to help L2 novice writers more easily realize and use citation forms in academic writings.

Bloch and Chi's (1995) study of the ways Chinese and Western academic writers refer to previous texts in their writing is a comparative study on evidentiality. They made a cross-cultural citation use comparison between American and Chinese academics across disciplines and examined the writing in social sciences and in the sciences. They examined the dates of citations (e.g., how recent were the texts referred to?), and whether the citations acted as background, support, and whether the use was critical. The findings revealed that American citation practices were noticeably different from those of the Chinese academics: the Chinese tended to use older texts; they used proportionately fewer citations. Although the science writers were similar in their use of citation strategies in both language groups, the Chinese social science writers used citations to support their arguments proportionately less than their American counterparts. Such findings corroborate the claim that writers from other cultures are likely to have some difficulties adapting to the writing conventions of British academia. Hyland's (1999) investigation of citation practices in academic writing is the closest to the study reported above. He quantified and analyzed the uses of integral and non-integral citation in a substantially-sized corpus of journal articles representative of eight disciplines. Among the features of citation practice that he looked at were:

- citation density in the texts

- surface form (integral vs. non-integral)

- the number, form and process category of reporting verbs

- quotation from other texts 
Hyland (1999) in this study investigated the differences in citation practices between writers of various disciplines, and his analysis was based on a view of academic writing as social interaction - that is, writers' motivations to make citations and to choose particular citation types are seen to be rhetorically driven, with the aim of achieving ratification by the disciplinary community of the new claims contained in the text. Hyland was interested in finding evidence of how writers react to different rhetorical contexts by making different rhetorical choices.

Hyland's (1998) paper, which was based on four different disciplines from a metatextual viewpoint, and his work (2004) on distribution of metadiscourse in a corpus of 240 doctoral and masters dissertations, investigated how academic writers employ language to imply reliable representation of their work in different disciplines.

Tadros's (1995) study on the use of citations in textbooks, and Berkenkotter and Huckin's (1995) study on the use of citation or referencing as a 'textual mechanism', which establishes the context and helps the writer to provide intertextual linkages, are other valuable attempts in this field.

\section{THEORETICAL FRAMEWORK}

The methodological framework offered in this study has been arrived at after a careful investigation of existing taxonomies and after applying them in ultimate model of this study. As mentioned earlier, the taxonomy proposed in this study was based on classifications of metadiscourse markers adapted by Hyland and Tse's (2004) combined with Swales' (1990) classification of citations as well as Berkenkotter and Huckin's (1995) concept of intertexuality in academic writing.

Upon this proposed taxonomy, EVs are then classified into two broad categories of Specific and Non-specific (see Fig. 1). A key role in this classification is played by 'Citation', or referencing, which according to Berkenkotter and Huckin (1995), is a 'textual mechanism' that establishes the context and helps the writer to provide 'intertextual linkages' and connect new findings to accepted knowledge. It plays an essential role in creating novelty by contextualizing new local knowledge within an ongoing history of disciplinary knowledge making.

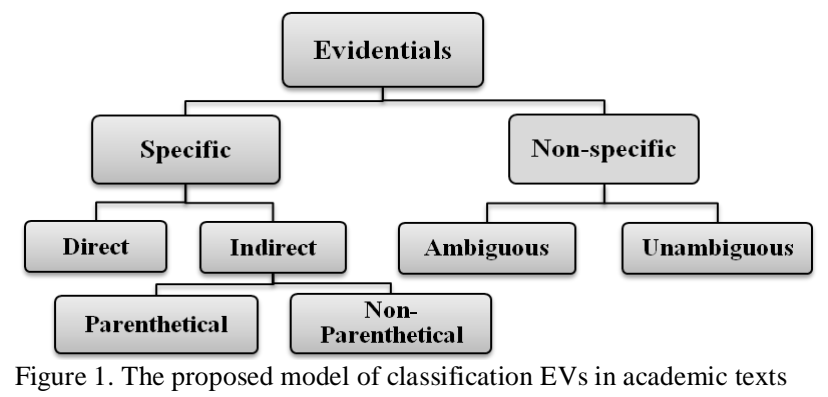

Specific category comprises those devices whose functions are providing a link between the author' own statements and other authors' statements, thus creating intertextuality. This group of EVs is further divided into two general categories of Direct and Indirect resources. Direct EVs include direct quotations of other sources placed within quotation marks (see example II.1). Indirect or non-quoted EVs, on the other hand, are the paraphrases or summaries of other author(s) utterances. These devices themselves are classified into two distinct categories: Non-parenthetical and Parenthetical. Non-parenthetical EVs are those which play an explicit grammatical role within a sentence and usually come at the beginning of the statements (e.g., According to X, Z states, cited, quoted, etc.) (see example II.2), and parenthetical EVs which are placed between parentheses, usually come at the end of statements and play no explicit grammatical role in the sentence (e.g., (date)/(name), [ref. no.]/ [name], (to) cite X, (to) quote X), (see examples II.3, II.4).

Non-specific EVs-on the other hand-include two categories of Ambiguous and Unambiguous EVs. Ambiguous EVs are those which emphasis on the established facts rather than who originally stated them or one's stance towards them, as a result, metadiscourse in this class of EVs is omitted and unspecified sources replace citations (e.g., It is generally believed that..., etc) (see example II.5). Unambiguous EVs appear as ambiguous EVs and the details of cited work(s) are not given in the text, but rather at the end of the statement. The citation provides a number of examples of studies that are referred to in the sentence. 'e.g.' or 'for example' typically prefaces the name(s) but not necessarily. In some other cases, however, citation refers the reader to a text to find further details. This form of citation usually comes with the word 'see' included in the parentheses at the end of the cited statement (e.g., some authors (e.g. the names of authors)), (see examples II.6, II.7)

It seems necessary for writers to realize that citation forms are purposeful; that is, for example, parenthetical EVs can be employed to emphasize the proposition (e.g., the finding, the data, the concept), and de-emphasize the researcher, the text, and/or piece of research by placing the citation outside the sentence, but this situation is quite different in nonparenthetical EVs, that is, a greater emphasis is placed on the researcher, the cited text, or the piece of research by including the citation in the sentence. 
One of the most important aspects of academic writing is making use of the ideas of other people. This is important as writers need to show that they have understood the materials they have studied and that they can use the other writers/speakers ideas and findings in their own way. In fact, this is an essential skill for every student. Spack (1988, p. 42) has pointed out that the most important skill a student can engage in is "the complex activity to write from other texts", which is "a major part of their academic experience." For this reason, any academic text we read or write will contain the voices of other writers as well as ours. The object of academic writing for writers is therefore to present their ideas in their own way. To this end, however, they will need to use the ideas of other people and for this purpose it will be necessary to say where the words and ideas are from.

Working with patterns, then, can be beneficial in raising student awareness of contextual factors and as a result, in enhancing their understanding of what lies behind the language choices evident on the page. It is very important for students to gain this insight into the extent and type of patterning found in written academic discourse, thus, the proposed model of this study for classifying EVs in academic writing can provide useful information for global professionals and advanced foreign language students and help them to write in a way which is not just grammatically correct, but also appropriate both for their specific purposes and within their disciplinary community. By examining the use of EVs, one may be able to assess better which types of sources play an important role in shaping the opinions of a particular culture or text. Thus, this study most of all, can help non-native speakers of English aiming to have their articles published in scholarly journals. Obviously, to this end, they need to observe the requirements of a good research article.

\section{REFERENCES}

[1] Abdi, R. (2002). Interpersonal metadiscourse: An indicator of interaction and identity. Discourse Studies, 4(2), 139-145.

[2] Abdi, R. (2009). Projecting cultural identity through metadiscourse marking; A comparison of Persian and English research articles. Journal of English language teaching and learning, 52(212), 1-15.

[3] Ädel, A. (2006). Metadiscourse in L1 and L2 English. Philadelphia: John Benjamins.

[4] Aikhenvald, A. (2004). Evidentiality. Oxford: Oxford University Press.

[5] Berkenkotter, C., \& Huckin, T. (1995). Genre knowledge in disciplinary communication. Hillsdale, IL: Lawrence Erlbaum Associates.

[6] Bloch, J., \& Chi, L. (1995). A comparison of the use of citations in Chinese and English academic discourse. In D. Belcher \& G. Braine. Academic Writing in a Second Language. Norwood, NJ, Ablex: 231-274.

[7] Borg, E. (2000). Citation practices in academic writing. In P. Thompson (Ed.), Patterns and perspectives: Insights for EAP writing practice. Reading, UK, CALS, University of Reading, London, UK.

[8] Britton, J., Burgess, T., Martin, N., McLeod, A., \& Rosen, H. (1975). The development of writing abilities, 11-18. London: Macmillan.

[9] Brooks, T. A. (1984). Private acts and public objects: An investigation of citer motivations. Journal of the American Society for Information Science, 36, 223-229.

[10] Brooks, T. A. (1986). Evidence of complex citer motivations. Journal of the American Society for Information Science, 37, 346.

[11] Budd, J. M. (1999). Citations and knowledge claims: Sociology of knowledge as a case in point. Journal of Information Science, 25(4), 265-274.

[12] Campbell, C. (1990). Writing with others words: Using background reading text in academic compositions. In B. Kroll (Ed.), Second Language Writing: Research insights for the classroom. Cambridge: Cambridge University Press.

[13] Cano, V. (1989). Citation behavior: Classification, utility, and location. Journal of the American Society for Information Science, 40, 284-290.

[14] Case, D. O., \& Higgins, G. M. (2000). How can I investigate citation behavior? A study of reasons for citing literature in communication. Journal of the American Society for Information Science, 51, 635-45.

[15] Charles, M. (2006). Phraseological patterns in reporting clauses used in citation: A corpus-based study of theses in two disciplines. English for Specific Purposes, 25(3), 310-331.

[16] Chubin, D. E., \& Moitra, S. D. (1975). Content Analysis of references: Adjunct or alternative to citation counting? Social Studies of Science, 5, 423-441.

[17] Cole, J., \& Cole, S. (1967). Scientific output and recognition: A study in the operation of the reward system in science. American Sociological Review, 32(3), 377-390.

[18] Cole, J., \& Cole, S. (1971). Measuring the quality of sociological research problems in the use of Science Citation Index. American Sociologist, 6(1), 23-29.

[19] Cole, J., \& Cole, S. (1976). The reward system of the social sciences. In C. Frankel (Ed.), Controversies and decisions: The Social Sciences and public policy (pp. 55-88). New York, NY: Russel Sage Foundation.

[20] Connor, U. (1999). Contrastive Rhetoric: Cross-cultural aspects of second language writing. Cambridge, UK: Cambridge University Press.

[21] Conrad, S. \& Biber, D. (2000). Adverbial marking of stance in speech and writing. In Evaluation in Text: Authorial Stance and the Construction of Discourse, S. Hunston and S. Thompson (Eds.), 56-73. Oxford: Oxford University Press.

[22] Cozzens, S. E. (1985). Comparing the sciences: Citation context analysis of papers from neuropharmacology and the sociology of science, Social Studies of Science, 15, 127-153.

[23] Cozzens, S. E. (1989). What do citations count? The rhetoric-first model. Scientometrics, 15, 437-447.

[24] Crismore, A. (1983). The rhetoric of social studies textbooks: Metadiscourse. (ERIC Document Reproduction in Service No. ED239 226). 
[25] Crismore, A. (1984). The case for a rhetorical perspective on learning from texts: Exploring metadiscourse. (ERIC Document Reproduction in Service No. ED257 035).

[26] Crismore, A. (1989). Talking with readers: Metadiscourse as rhetorical act. New York: Peter Lang Publishers.

[27] Crismore, A. (1990). Metadiscourse and discourse processes: Interactions and issues. Discourse Processes, 13(2): 191-205.

[28] Crismore, A., \& Farnsworth, R. (1990). Metadiscourse in popular and professional science discourse. In W. Nash (Ed), The Writing scholar: Studies in academic discourse (pp. 118-36). Newbury Park, CA: Sage.

[29] Crismore, A., Markkanen, R., \& Steffensen, M. (1993). Metadiscourse in persuasive writing: A study of texts written by American and Finnish university students. Written Communication, 10, 39-71.

[30] Cronin, B. (1998). Metatheorizing citation. Scientometrics, 43(1), 45-55.

[31] Dafouz-Milne, E. (2003). Metadiscourse revisited: A contrastive study of persuasive writing in professional discourse. Estudios Ingleses de la Universidad Complutense, 11, 29-52.

[32] Dafouz-Milne, E. (2008). The pragmatic role of textual and interpersonal metadiscourse markers in the construction and attainment of persuasion: A cross-linguistic study of newspaper discourse. Journal of Pragmatics, 40, 95-113.

[33] Dahl, T. (2004). Textual metadiscourse in research articles: A marker of national culture or of academic discipline? Journal of Pragmatics, 36, 1807-1825.

[34] Davenport, E., \& Cronin, B. (2000). The citation network as a protoreason for representing trust in virtual environments. In B. Cronin \& H. B. Atkins (Eds.), The Web of knowledge: A festschrift in Honor of Eugene Garfield (pp. 517-534). New Jersey, Information Today, Inc.

[35] Dendale, P., \& Tasmowski, L. (2001). Introduction: evidentiality and related notions. Journal of Pragmatics, 33, 339-348.

[36] Faghih, E., \& Rahimpour, S. (2009). Contrastive rhetoric of English and Persian written texts: Metadiscourse in applied linguistics research articles. Rice Working Papers in Linguistics, 1, 92-107.

[37] Fox, H. (1994). Listening to the world: Cultural issues in academic writing. Urbana, IL: National Council of Teachers of English.

[38] Fuertes-Olivera, P. A., Velasco-Sacristán, M., Arribas-Baño, A., \& Samiengo-Fernández, E. (2001). Persuasion and advertising English: Metadiscourse in slogans and headlines. Journal of Pragmatics, 33, 1291-1307.

[39] Gilbert, G. N. (1977). Referencing as persuasion. Social Studies of Science, 7(1), 113-122.

[40] Groom, N. (2000). Attribution and averral revisited: Three perspectives on manifest intertextuality in academic writing. In P. Thompson (Ed.), Patterns and perspectives: Insights into EAP writing practice (pp. 14-25). Reading: University of Reading, London, UK.

[41] Halliday, M. A. K. (1973). Exploring in the functions of language. London: Arnold.

[42] Halliday, M. A. K. (1985). Spoken and written language. Oxford: Oxford University Press.

[43] Hardman, M. J. (1986). Datasource marking in the Jaqi languages. In W. Chafe \& J. Nichols (Eds.), Evidentiality: The linguistic coding of epistemology, 113-136. Norwood, NJ: Ablex.

[44] Harwood, N. (2004). Citation analysis: a multidisciplinary perspective on academic literacy. In M. Baynham, A. Deignan, \& G. White (Eds.) Applied linguistics at the interface (pp.79-89). London: BAAL and Eqinox.

[45] Hunston, S., \& Thomspon, G. (2003). Evaluation in Text. Oxford University Press.

[46] Hyland, K. (1998). Persuasion and context: the pragmatics of academic metadiscourse. Journal of Pragmatics, 30(4), 437-455.

[47] Hyland, K. (1999). Academic attribution: Citation and the construction of disciplinary knowledge. Applied Linguistics, 20(3), 341-367.

[48] Hyland, K. (1999). Hedging in scientific research articles. Amsterdam: John Benjamins

[49] Hyland, K. (2000). Disciplinary discourses: Social interaction in academic writing. London: Pearson.

[50] Hyland, K. (2001). Humble servants of the discipline? Self-mention in research articles. English for Specific Purposes, 20(3), 207-26.

[51] Hyland, K. (2004). Patterns of engagement: Dialogic features and L2 student writing. In L. Ravelli \& R. Ellis (Eds.), Academic writing in context: social-functional perspectives on theory and practice. London: Continuum.

[52] Hyland, K. (2005). Metadiscourse: Exploring interaction in writing. Continuum: London.

[53] Hyland, K., \& Tse, P. (2004). Metadiscourse in academic writing: a reappraisal. Applied Linguistics, 25(2), 156-77.

[54] Latour, B. (1987). Science in action: how to follow scientists and engineers through society. Cambridge, Massachusetts: Harvard University Press.

[55] Liu, M. (1993). Progress in documentation the complexities of citation practice: A review of citation studies. Documentation, $49,370-408$

[56] Liu, Z. (1997). Citation theories in the framework of international flow of information. New Evidence with Translation Analysis, 48(1), 80-87.

[57] MacRoberts, M. H., \& MacRoberts, B. R. (1984). The negational reference or the art of dissembling. Social Studies of Science, $14,91-94$

[58] Mauranen, A. (1993a). Cultural differences in academic rhetoric: A text linguistic study. Frankfurt am Main: Peter Lang Publishers.

[59] Merton, R. K. (1973). The sociology of science: theoretical and empirical investigations. Chicago: University of Chicago Press.

[60] Moravcsik, M. J., \& Murugesan, P. (1975). Some results on the function and quality of citations. Social Studies of Science, 5 , $86-92$.

[61] Myers, G. (1990). Writing biology: Texts in the social construction of science. Madison, WI: University of Wisconsin Press.

[62] Okamura, A., \& Shaw, P. (2000). Lexical phrases, culture, and sub-culture in transactional letter writing. English for specific purposes, 19, 1-15.

[63] Pennycook, A. (1996). Borrowing others' words: Text, ownership, memory, and plagiarism. TESOL Quarterly, 30(2), 201-230.

[64] Salager-Meyer, F. (1992). A text-type and move analysis study of verb tense and modality distributions in medical English abstracts. English for Specific Purposes, 11, 93-133. 
[65] Shadish, W. R., Tolliver, D., Gray, M. \& Gupta, S. K. (1995). Author judgments about works they cite: Three studies from psychology journals. Social Studies of Science, 25, 477-98.

[66] Shaw, P. M. (1992). Reasons for the correlation of voice, tense and sentence function in reporting verbs. Applied Linguistics, 13, 302-317.

[67] Simin, S. (2004). Metadiscourse knowledge and use in Iranian EFL writing. Unpublished Master's thesis, University of Isfahan, Isfahan, Iran.

[68] Simin, S., \& Tavangar, M. (2009). Metadiscourse knowledge and use in Iranian EFL writing. The Asian EFL Journal Quarterly, $11(1), 230-255$

[69] Small, H. (1982). Citation context analysis. In B. Dervin \& M. J. Voigt (Eds.), Progress in communication sciences 3, (pp. 287310). Norwood, NJ: Ablex.

[70] Spack, R. (1988). Initiating ESL Students into the Academic Discourse Community: How Far Should We Go? TESOL Quarterly, 22(1), 29-51.

[71] Steffensen, M. S., \& Cheng, X. (1996). Metadiscourse and text pragmatics: How students write after learning about metadiscourse. In L. F. Bouton, (Ed.), Pragmatics and language learning. Monograph series: 7, (pp. 153-171). (ERIC Document Reproduction in Service No. ED 400 709).

[72] Swales, J. M. (1986). Citation analysis and discourse analysis. Applied Linguistics, 7(1), 39-56.

[73] Swales, J. M. (1990). Genre Analysis: English in Academic and Research Settings. Cambridge: Cambridge University Press.

[74] Tadros, A. (1995). The pragmatics of text averral and attribution in academic texts. In M. Hoey (Ed.), Data, description, discourse (pp. 98-114.). Harper Collins Publishers.

[75] Taylor, T. J. (2000). Language constructing language: The implications of reflexivity for linguistic theory. Language Sciences, 22, 483-499.

[76] Thomas, S., \& Hawes, T. P. (1994). Reporting verbs in medical journal articles. English for Specific Purposes, 13, 129-148.

[77] Thompson, G. (2001). Introduction in academic writing: learning to argue with the reader. Applied Linguistics, 22(1), 58-78.

[78] Thompson, G., \& Thetela, P. (1995). The sound of one hand clapping: The management of interaction in written discourse. Text, 15(1), 103-127.

[79] Thompson, G., \& Ye, Y. (1991). Evaluation in the reporting verbs used in academic papers. Applied Linguistics, 12, $365-382$.

[80] Thompson, P., \& C. Tribble (2001). Looking at citations: Using corpora in English for Academic Purposes. Language Learning and Technology, 5(3), 91-105.

[81] Thomspon, G. (1996). Voice in the Text: Discourse perspectives on language reports. Applied Linguistics, 17, 501-30.

[82] Thomspon, P., (2006). Towards a sociocognitive model of progression in spoken English. Cambridge Journal of Education, $36(2), 207-220$.

[83] Vande Kopple, W. J. (1985). Some explanatory discourse on metadiscourse. College Composition and Communication, 36, 8293.

[84] Vande Kopple, W. J. (1988). Metadiscourse and the recall of modality markers. Visible Language, 22(2/3), 232-267.

[85] Vande Kopple, W. J. (2002). Metadiscourse, discourse, and issues in composition and rhetoric. In F. Barton \& C. Stygall (Eds.), Discourse Studies in Composition (pp. 91-113). Cresskill, NJ: Hampton Press.

[86] Vinkler, P. (1998). Comparative investigation of frequency and strength of motives toward referencing: The reference threshold model. Scientometrics, 43, 107-127.

[87] Wang, P., \& White, M. D. (1997). A qualitative study of citing behavior: Contributions, criteria, and metalevel documentation concerns. Library Quarterly, 67, 122-154.

[88] Wang, P., \& White, M. D. (1999). A Cognitive model of document use during a research project. Journal of the American Society for Information Science, 50(2), 98-114.

[89] White, H. D. (2004). Citation analysis and discourse analysis revisited. Applied Linguistics, 25(1), 89-116.

[90] Zuckerman, H. (1987). Citation analysis and the complex problem of intellectual influence. Scientometrics, 12(5-6), 38-930.

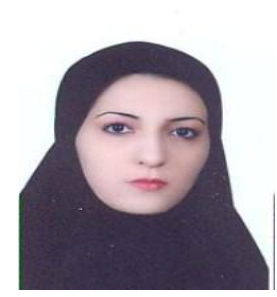

Mojdeh Ebrahimi Dehkordi received her B.A in English Translation from Khorasgan Azad University, Isfahan, Iran in 2005. She started her M.A studies in TEFL at Islamic Azad University, Shahreza Branch, Iran in 2008 and graduated from this university with honors in 2011. In her M.A thesis she proposed a new model for Evidentials in academic texts and successfully defended it. Her current research interests lie in the areas of metadiscourse, cross-cultural studies, rhetoric and discourse analysis. She has already presented articles in international TELLSI conferences.

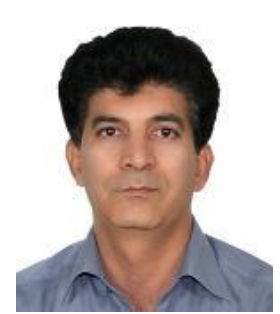

Hamid Allami, Ph.D. is assistant professor of Applied Linguistics at Yazd University, Iran. His major areas of research include sociopragmatics, speech acts and interlanguage pragmatics. He has already published many articles in both national and international journals such as TELL, IJLS, Iranian EFL Journal, Linguistics Journal, and Journal of Pragmatics. He has also been a reviewer of articles to several journals such as Applied Linguistics, TELL and IJLS. 